\title{
Mild Neonatal Hypoxia Exacerbates the Effects of Vitamin-Deficient Diet on Homocysteine Metabolism in Rats
}

\author{
SÉBASTIEN BLAISE, JEAN-MARC ALBERTO, EMMANUELLE NÉDÉLEC, AHMET AYAV, \\ GRÉGORY POURIÉ, JEAN-PIERRE BRONOWICKI, JEAN-LOUIS GUÉANT, AND \\ JEAN-LUC DAVAL \\ INSERM U 724, Université H. Poincaré, Faculté de Médecine, BP 184, 54505 Vandoeuvre-lès-Nancy \\ Cedex, France
}

\begin{tabular}{|c|c|}
\hline \multicolumn{2}{|c|}{ ABSTRACT } \\
\hline $\begin{array}{l}\text { Elevated plasma homocysteine has been linked to pregnancy } \\
\text { complications and developmental diseases. Whereas hyperhomo- } \\
\text { cysteinemia is frequently observed in populations at risk of } \\
\text { malnutrition, hypoxia may alter the remethylation of homocys- } \\
\text { teine in hepatocytes. We aimed to investigate the combined } \\
\text { influences of early deficiency in nutritional determinants of } \\
\text { hyperhomocysteinemia and of neonatal hypoxia on homocys- } \\
\text { teine metabolic pathways in developing rats. Dams were fed a } \\
\text { standard diet or a diet deficient in vitamins B12, B2, folate, } \\
\text { month, and choline from } 1 \text { mo before pregnancy until weaning of } \\
\text { the offspring. The pups were divided into four treatment groups } \\
\text { corresponding to "no hypoxia/standard diet," "hypoxia ( } 100 \% \\
\mathrm{~N} 2 \text { for } 5 \text { min at postnatal d } 1) / \text { standard diet," "no hypoxia/ } \\
\text { deficiency," and "hypoxia/deficiency," and homocysteine metab- } \\
\text { olism was analyzed in their liver at postnatal d } 21 \text {. Hypoxia } \\
\text { increased plasma homocysteine in deficient pups }(21.2 \pm 1.6 \\
\text { versus } 13.3 \pm 1.2 \mu \mathrm{M}, p<0.05) \text {. Whereas mRNA levels of } \\
\text { cystathionine } \beta \text {-synthase remained unaltered, deficiency reduced } \\
\text { the enzyme activity ( } 48.7 \pm 2.9 \text { versus } 83.6 \pm 6.3 \text { nmol/h/mg, } p \\
<0.01) \text {, an effect potentiated by hypoxia ( } 29.4 \pm 4.7 \text { nmol/h/mg, } \\
p<0.05) \text {. The decrease in methylene-tetrahydrofolate reductase } \\
\text { activity measured in deficient pups was attenuated by hypoxia }(p\end{array}$ & $\begin{array}{l}<0.05) \text {, and methionine-adenosyltransferase activity was } \\
\text { slightly reduced only in the "hypoxia/deficiency" group }(p< \\
\text { 0.05). Finally, hypoxia enhanced the deficiency-induced drop } \\
\text { of the S-adenosylmethionine/S-adenosylhomocysteine ratio, } \\
\text { which is known to influence DNA methylation and gene } \\
\text { expression. In conclusion, neonatal hypoxia may increase } \\
\text { homocysteinemia mainly by decreasing homocysteine trans- } \\
\text { sulfuration in developing rats under methyl-deficient regimen. } \\
\text { It could therefore potentiate the well-known adverse effects of } \\
\text { hyperhomocysteinemia. (Pediatr Res 57: 777-782, 2005) } \\
\text { BHMT, betaine-homocysteine-methyltransferase } \\
\text { CBS, cystathionine } \beta \text {-synthase } \\
\text { HCY, homocysteine } \\
\text { hHCY, hyperhomocysteinemia } \\
\text { MAT, methionine-adenosyltransferase } \\
\text { MS, methionine synthase } \\
\text { MTHFR, methylene-tetrahydrofolate reductase } \\
\text { NO, nitric oxide } \\
\text { SAH, S-adenosylhomocysteine } \\
\text { SAM, S-adenosylmethionine }\end{array}$ \\
\hline
\end{tabular}

Plasma accumulation of $\mathrm{HCY}$ is known to be linked to cardiovascular diseases and ageing-associated disabilities (13). Moderate hHCY can arise from genetic determinants $(4,5)$ but is also frequently related to dietary deficiency in vitamins $\mathrm{B} 12$, B2, and folate. In newborns, the risk of hHCY is closely related to elevated maternal $\mathrm{HCY}$ concentrations during pregnancy, which is determined by the status of B vitamins (6-8).

Received July 14, 2004; accepted October 13, 2004.

Correspondence: Jean-Luc Daval, Ph.D., INSERM U 724, Faculté de Médecine, 9 Avenue de la Forêt de Haye, B.P. 184, 54505 Vandoeuvre-les-Nancy Cedex, France; e-mail: Jean-Luc.Daval@nancy.inserm.fr

The present work was funded by INSERM. S.B. is indebted to the "Région Lorraine" for financial support.

DOI: 10.1203/01.PDR.0000161406.19231.98
A strong relationship has been documented between HCY accumulation and pregnancy complications, including recurrent miscarriages, preeclampsia, and placenta abruption (see Ref. 9 for review). In the progeny, hHCY has been associated with fetal death (10), premature birth (11), intrauterine growth retardation (12), neural tube defects (13), craniofacial anomalies (14), cardiac malformation (15), and hepatic steatosis (16).

HCY production involves the demethylation of methionine, and, under normal conditions, is essentially regulated in the liver. As summarized in Figure 1, it originates from the hydrolysis of $\mathrm{SAH}$, a product of transmethylation reactions through SAM, and is metabolized via two pathways of remethylation and one pathway of transsulfuration. HCY metabolism strongly depends on the nutritional intake of B vitamins, 


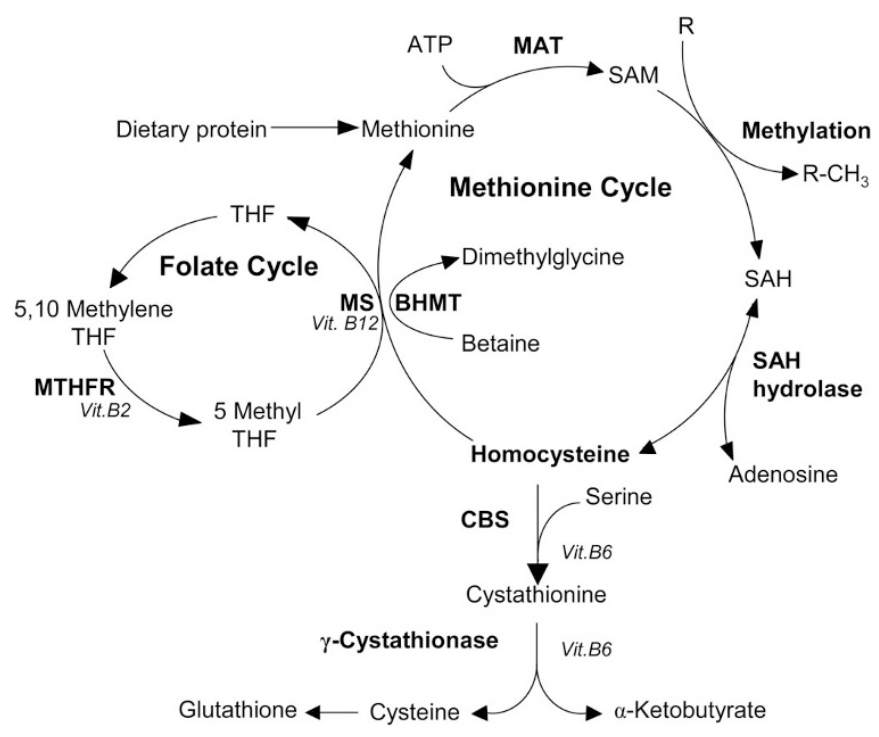

Figure 1. Homocysteine metabolism. $R$, radical; Vit., vitamin.

inasmuch as remethylation of HCY into methionine is catalyzed by a vitamin B12- and folate-dependent enzyme, namely the MS, and, in the liver, by BHMT. MTHFR is a flavoprotein dependent on vitamin B2, which reduces methylenetetrahydrofolate into methyl-tetrahydrofolate, the co-substrate of MS. The second part of the methionine cycle successively involves the synthesis of SAM from methionine by MAT and the transmethylation of SAM, producing SAH. Transsulfuration involves a condensation of $\mathrm{HCY}$ with serine by CBS to generate cystathionine, a cysteine precursor (17).

Several reports have outlined that hypoxia and/or ischemia may alter the remethylation pathway of HCY and, more particularly, the adenosylation of HCY (18-21). Decreased concentration of SAM and reduced expression of MAT have been reported in adult rats as well as in isolated rat hepatocytes under moderate chronic hypoxia (18-21). In the adult rat, a significant SAM deficit was recorded after $10 \mathrm{~d}$ of hypoxia, and this was associated with DNA hypomethylation. The authors suggested that hypoxia would result in a decreased methylation similar to that produced by a methyl-deficient diet (19). However, no data are currently available on the effects of transient hypoxia on the liver activity of the key enzymes involved in the remethylation pathway (i.e. MTHFR, MS, and BHMT) and in the transsulfuration pathway (i.e. CBS). Considering that both hHCY and acute hypoxia may simultaneously occur in neonates, particularly in some populations at risk of malnutrition (22-25), we aimed to evaluate the effects of transient neonatal hypoxia on liver HCY metabolism in a rat model of nutritionally induced $\mathrm{hHCY}$ during pregnancy.

\section{METHODS}

Animals and exposure to hypoxia. Animal treatments were performed according to the National Institutes of Health Guide for the Care and Use of Laboratory Animals. Female Wistar rats (Charles River, Les Oncins, France) were constantly maintained under standard laboratory conditions, with food and water available ad libitum. One month before pregnancy, they were fed either with standard food $(n=8)$ (Maintenance diet M20, Scientific Animal Food and Engineering, Villemoisson-sur-Orge, France) containing vitamins B12 $(0.04 \mathrm{mg} / \mathrm{kg})$, B2 $(13 \mathrm{mg} / \mathrm{kg})$, folate $(0.9 \mathrm{mg} / \mathrm{kg})$, methionine $(4800$ $\mathrm{mg} / \mathrm{kg}$ ) and choline (2100 mg/kg), according to the manufacturer, or with a diet deprived of vitamins B12, B2, folate, and choline $(n=8)$ (Special Diet Service, Saint-Gratien, France). Before mating, blood samples were drawn from caudal vessels under halothane anesthesia for the measurement of plasma vitamin B12 and folate concentrations.

Within $24 \mathrm{~h}$ after delivery, the litter size was reduced to 10 pups for subsequent standardization of the study. Half of the neonates were placed for $5 \mathrm{~min}$ in a Plexiglas chamber thermostated at $36^{\circ} \mathrm{C}$ and flushed with $100 \% \mathrm{~N}_{2}$, whereas the remaining pups were used as controls and exposed to $21 \% \mathrm{O}_{2} / 79 \%$ $\mathrm{N}_{2}$ (normoxic conditions) for the same time. Pups were then allowed to recover for $20 \mathrm{~min}$ in normoxia before being returned to their dams. Preliminary studies showed that such a short hypoxia did not induce detectable brain lesions (26). When used, deficient diet was given to dams until weaning of their offspring, i.e. $21 \mathrm{~d}$ after birth.

A total of 48 pups was divided into four experimental groups: C (control) $=$ rats not subjected to hypoxia and fed by a dam with standard diet; $\mathrm{H}$ $($ hypoxia $)=$ rats exposed to hypoxia and fed by a dam receiving standard diet; $\mathrm{D}($ deficient $)=$ nonhypoxic rats fed by a dam with a deficient diet; and HD (hypoxia-deficient $)=$ rats exposed to hypoxia and fed by a dam with a deficient diet.

Sample collection. For subsequent studies, pups were killed at $21 \mathrm{~d}$ of age by exposure to excess halothane. Intracardiac blood samples were drawn for the measurement of vitamin B12, folate, and HCY plasma concentrations. The liver was rapidly collected, washed in Ringer buffered solution $(2 \mathrm{mM} \mathrm{KCl}$, $125 \mathrm{mM} \mathrm{NaCl}, 2 \mathrm{mM} \mathrm{CaCl}, 1 \mathrm{mM} \mathrm{MgCl}, 1.25 \mathrm{mM} \mathrm{NaH}_{2} \mathrm{PO}_{4}, 26 \mathrm{mM}$ $\mathrm{NaHCO}_{3}, 2 \mathrm{~g} / \mathrm{L}$ glucose, $\mathrm{pH}$ 7.3) and frozen in liquid nitrogen. Liver cells were lysed at $4^{\circ} \mathrm{C}$ in $100 \mathrm{mM}$ potassium phosphate buffer $(\mathrm{pH}$ 7.3) containing protease inhibitors (Proteases inhibitor cocktail, Sigma Chemical Co., St. Louis, MO). Proteins samples were quantified according to Bradford (27).

Plasma metabolite concentrations. Plasma vitamin B12 and folate concentrations were determined by radio-dilution isotope assay (simulTRAC-SNB, ICN Pharmaceuticals, Costa Mesa, CA) (6). HCY concentration was assessed by fluorescent polarization immunoassay (IMX system, Abbott Norge AS, Billingstad, Norway) (28).

Activities of enzymes involved in homocysteine metabolism and hepatic metabolites. All measurements described below were performed with tissue samples corresponding to $400 \mu \mathrm{g}$ of total proteins. CBS was measured by a method adapted from Taoka et al. (29). Proteins were incubated for $30 \mathrm{~min}$ at $37^{\circ} \mathrm{C}$ in a reactive solution [0.1 M Tris ( $\left.\mathrm{pH} 8.5\right), 1 \mathrm{mM}$ cystathionine, $5 \mathrm{mM}$ D,L-serine (Sigma Chemical Co.), $1 \mathrm{mM}$ pyridoxal 5'-phosphate, $0.25 \mu \mathrm{Ci}$ $\left[{ }^{14} \mathrm{C}\right]$ serine (Amersham Biosciences, Saclay, France), and $15 \mathrm{mM} \mathrm{HCY}$ (Sigma Chemical Co.)]. After washing with $20 \mathrm{mM}$ maleic acid (pH 1.9) and $0.2 \mathrm{M} \mathrm{LiCl}$, radiolabeled cystathionine was eluted with $50 \mathrm{mM}$ acetic acid $(\mathrm{pH}$ 4.8), 0.8 M LiCl into Dowex 50WX2-200 gel (Sigma Chemical Co.), and quantified by means of a liquid scintillation analyzer (Packard Biosciences, Meriden, CT,). MS activity was monitored by a method adapted from Chen and Banerjee (30). Proteins were incubated in a buffered solution $[100 \mathrm{mM}$ $\mathrm{KH}_{2} \mathrm{PO}_{4}$ (pH 7.2), $25 \mathrm{mM}$ DTT, $25 \mathrm{mM}$ ascorbate, $0.5 \mathrm{mM} \mathrm{SAM}, 50 \mu \mathrm{M}$ $\mathrm{OH}$-cobalamin, $5 \mathrm{mM} \mathrm{D}, \mathrm{L}-\mathrm{HCY}$, and $250 \mu \mathrm{M}\left[{ }^{14} \mathrm{CH}_{3}\right]$ methyl-tetrahydrofolate]. Eluted on a cationic gel (quaternary ammonium, $\mathrm{AG} 1 \times 8, \mathrm{Cl}^{-}$form, Bio-Rad), $\left[{ }^{14} \mathrm{CH}_{3}\right]$ methionine was measured with PicoFluor-40 (Packard Biosciences). Enzymatic activity of BHMT was measured as previously described by Garrow (31). MAT activity was measured according to Chamberlin et al. (32). The activity of MTHFR was measured as reported by Kutzbach and Stokstad (33).

For the measurement of SAM and SAH concentrations, the technique was adapted from Delabar et al. (34). Proteins were precipitated with $0.2 \mathrm{~N} \mathrm{HClO}_{4}$, before injection on the column (Lichrospher, $100 \mathrm{RP}-\mathrm{C} 18,5 \mu \mathrm{m}, 250 \times 4 \mathrm{~mm}$ ID). The mobile phase was applied at a flow rate of $0.75 \mathrm{~mL} / \mathrm{min}$ and consisted in $50 \mathrm{mM}$ sodium phosphate $(\mathrm{pH} 3.2), 10 \mathrm{mM}$ heptan sulfonate, and acetonitrile (10-20\% from 0 to $20 \mathrm{~min})$. Amounts of SAM and SAH were quantified by using an UV detector at $254 \mathrm{~nm}$.

MS and CBS mRNA assays. Total RNA were isolated from liver tissues using the Rneasy mini-kit from QIAGEN (Courtaboeuf, France) according to the manufacturer's protocol, and quantified by spectrophotometry. RNA integrity was assessed by subjecting $1 \mu \mathrm{g}$ of total RNA to electrophoresis through a $1 \%(\mathrm{wt} / \mathrm{vol})$ agarose gel. Total RNA $(2 \mu \mathrm{g})$ was reverse-transcribed using hexamer random primers and Omniscript (QIAGEN) in a $20-\mu \mathrm{L}$ volume reaction of a buffered mixture containing $0.5 \mathrm{mM}$ dNTP. The cDNA products were 2 -fold diluted, and $2 \mu \mathrm{L}$ was used as a template for each amplification in PCR. Reactions were performed with TaqDNA polymerase (Invitrogen, Cergy Pontoise, France) in $50 \mu \mathrm{L}$ of a buffered solution containing $0.5 \mathrm{mM}$ dNTP, and $0.5 \mu \mathrm{M}$ of each primer. Separate PCR for MS, CBS, and L-27 (internal standard) amplification were undertaken with the following oligonucleotides primers: MS (NM 030864, 228 bp product), sense 5'CAGATATAATTGGCTTGTCAGGACT3', antisense 5'TTTCATCTAACAGCTGAGAACACAC3'; CBS (NM 012522, 350 bp product), sense 5'TTCCCCACATTACCACACAG3', antisense 5'AGCACATCCACCTTCTCCAT3'; and L-27 (NM 
022514, 364 bp product), sense 5'GCTGTCGAAATGGGCAAGTT3', antisense 5'CAAACTTGACCTTGGCCTCC3'. Conditions of PCR allowing to be in the exponential phase of PCR were as follows: for MS, number of cycles $(n)$ $=31$, annealing temperature $(\mathrm{AT})=61^{\circ} \mathrm{C}$; for $\mathrm{CBS}, n=30$, AT $=56^{\circ} \mathrm{C}$; for $\mathrm{L}-27, n=27, \mathrm{AT}=62^{\circ} \mathrm{C}$. Amplification products were analyzed by agarose gel electrophoresis, visualized by ethidium bromide staining, and quantified by densitometry with ImageMaster 1D Primer software and ImageMaster apparatus (Amersham Pharmacia Biotech, Quebec, Canada). Amplicons selectively amplified the desired target mRNA, and results were expressed relatively to the mRNA levels of the housekeeping gene $L-27$.

Statistical analyses. Data were prospectively collected and analyzed with Statview 5 software for Windows (SAS Institute, Berkley, CA). Reported as mean $\pm \mathrm{SD}$, raw data were compared by using one-way ANOVA with Fisher's test. Multiple regression and univariate z-correlation analyses were used to evaluate the relationships between enzymatic activities, plasmatic or intracellular metabolites, and animal weight and size. A $p$ value $<0.05$ was considered to indicate statistical significance.

\section{RESULTS}

General observations. In some experiments, evidence of hypoxia in neonates was detected by the measurement of blood gases $\left(\mathrm{pH}, \mathrm{PO}_{2}\right.$, and $\left.\mathrm{P}_{2}\right)$, as previously described (35). At the end of exposure to hypoxia (or to normoxia for controls), mixed blood samples were rapidly collected following decapitation, sheltered from ambient air, and injected into a gas analyzer (Corning Medical and Scientific, Halstead, UK). Immediately after hypoxia, a significant hypoxemia was recorded $\left(\mathrm{Po}_{2}=40.6 \pm 5.3\right.$ versus $\left.62.5 \pm 6.1 \mathrm{~mm} \mathrm{Hg}, n=5, p<0.01\right)$, along with mild hypercapnia $\left(\mathrm{PCO}_{2}=49.2 \pm 6.1\right.$ versus $33.7 \pm$ $5.8 \mathrm{~mm} \mathrm{Hg}, p<0.05)$ and acidosis $(\mathrm{pH}=7.23 \pm 0.04$ versus $7.38 \pm 0.02, p<0.01)$. The hypoxic episode did not affect pups' survival and had no apparent consequences on their subsequent growth (Fig. 1).

Whereas the deficient diet was without lethal effects in pregnant females, it led to $25 \%$ perinatal mortality in offspring. In addition, this regimen induced a significant growth retardation that was observable until the end of the suckling period. Starting from the first day after birth, the body weight was significantly lower in animals belonging to groups D and HD when compared with those from groups $\mathrm{C}$ and $\mathrm{H}$, and the difference increased with time until d 21 (Fig. 2, Table 1). The

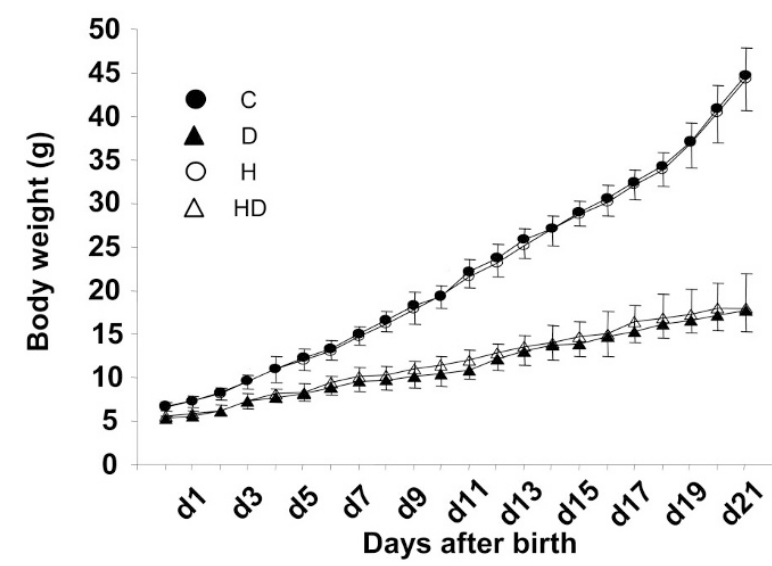

Figure 2. Influence of deficient regimen and hypoxia on the evolution of rat body weight during postnatal development. Data are mean \pm SD. For each experimental group, 12 rats from four different litters were studied. Statistically significant differences at all points (ANOVA): $p<0.01$ (deficient regimen $v s$ normal regimen in nonhypoxic animals), $p<0.01$ (deficient regimen $v s$ normal regimen in hypoxic animals). decrease in weight gain was accompanied by a reduced size in rat pups. The close correlation $(\mathrm{z}=6.113, p<0.0001)$ between the two parameters (size and body weight) confirmed a global growth retardation in response to the deficient diet rather than a malnutrition-related thinness.

Vitamin status. Concentrations of vitamin B12 and folate were measured in blood samples of adult female rats to evaluate the influence of diet (Table 1). At the time of mating (i.e. $30 \mathrm{~d}$ after the beginning of exposure to specific dietary regimens), the deficient diet significantly decreased plasma concentrations of vitamin B12 $(p<0.01)$ and folate $(p<0.01)$.

The maternal regimen clearly influenced vitamin concentrations in offspring (Table 1). At $21 \mathrm{~d}$ of age, rats belonging to groups D and HD displayed a $72 \%$ decrease of plasma vitamin B12 concentration compared with the two groups fed normally $(p<0.01)$. In parallel, plasma folate concentration was reduced by $61 \%(p<0.01)$. Irrespectively of the nutritional diet, hypoxia had no influence on vitamin B12 plasma concentration, but it appeared to decrease folate concentration in $\mathrm{H}$ group compared with controls $(p<0.05)$.

Homocysteine and metabolic alterations. As expected, homocysteinemia rose in dams fed with the deficient diet $(p<$ 0.01 ) (Table 1). Similarly, the decline of vitamin B12 and folate concentrations in offspring fed by a deprived mother was associated with substantial increases in HCY plasma levels. At $21 \mathrm{~d}$ of age, these young rats exhibited HCY concentrations two times higher than those found in their normally fed counterparts (Table 1). Whereas hypoxia did not influence homocysteinemia in normally fed rat pups, it was shown to potentiate the diet effects by significantly increasing hHCY in the HD group compared with group D (Table 1).

As illustrated by Figure 3, a global reduction of $\mathrm{HCY}$ catabolism seemed to account for the observed increased homocysteinemia in young rats exposed early to an unbalanced regimen. Indeed, rats from group D showed a substantial decrease of CBS activity when compared with controls (48.6 \pm 2.9 versus $83.6 \pm 6.3 \mathrm{nmol} / \mathrm{h} / \mathrm{mg}, p<0.01$ ). This drop was more pronounced when deficient neonates were transiently exposed to hypoxia $(29.4 \pm 4.7 \mathrm{nmol} / \mathrm{h} / \mathrm{mg}$ in $\mathrm{HD}$ group), whereas hypoxia alone did not alter CBS activity.

The MS enzyme was also dramatically affected by the nutritional conditions, its activity varying from $2.5 \pm 0.3 \mathrm{nmol} / \mathrm{h} / \mathrm{mg}$ in group $\mathrm{C}$ to $0.6 \pm 0.1 \mathrm{nmol} / \mathrm{h} / \mathrm{mg}$ in group $\mathrm{D}(p<0.01)$. Hypoxia had no significant influence on this enzyme, whatever the nutritional status. In contrast to the two other pathways of HCY degradation, the remethylation pathway involving BHMT was found to be unchanged among the four animal groups, BHMT activity remaining stable around $7.5 \mathrm{nmol} / \mathrm{h} / \mathrm{mg}$.

Neither the deficient diet nor hypoxia alone significantly affected MAT activity, but combined treatments decreased it (Fig. 3). SAM concentration was significantly reduced in rats exposed to the deficient diet (from $102.9 \pm 13.5 \mu \mathrm{g} / \mathrm{mg}$ protein in group $\mathrm{C}$ to $64.6 \pm 9.6 \mu \mathrm{g} / \mathrm{mg}$ protein in group $\mathrm{D}, p<0.01)$. Although hypoxia by itself did not affect SAM concentrations in rats with normal regimen, it appeared to potentiate the consequences of the deficient diet, with SAM concentration reaching $29.8 \pm 5.0 \mu \mathrm{g} / \mathrm{mg}$ protein in these conditions. By contrast, SAH concentrations did not vary throughout the 
Table 1. Effects of the nutritional regimen on weight, size, and plasma vitamin B12, folate, and HCY concentrations in adult female rats and their offspring

\begin{tabular}{|c|c|c|c|c|c|c|c|c|}
\hline & \multicolumn{2}{|c|}{ Adult females (d 0) } & \multicolumn{2}{|c|}{ Adult females (d 30) } & \multicolumn{4}{|c|}{ Progeny (postnatal d 21) } \\
\hline & Normal diet & Deficient diet & Normal diet & Deficient diet & $\mathrm{C}$ & $\mathrm{H}$ & $\mathrm{D}$ & HD \\
\hline Weis & $227.2 \pm 1.6$ & $234.3 \pm 15.1$ & $268.2 \pm 15.3^{*}$ & $259.3 \pm 15.0 *$ & $44.7 \pm 3.0$ & $44.2 \pm 3.5$ & $17.7 \pm 4.3 \dagger$ & $18.0=$ \\
\hline Vitamin B12 (pmol/L) & $1078.8 \pm 107.0$ & $989.2 \pm 91.7$ & $1057.5 \pm 177.8$ & $555.8 \pm 99.3 \dagger$ & $1202.5 \pm 161.4$ & $1207.9 \pm 112.6$ & $333.6 \pm 61.0 \dagger$ & $322.8 \pm 68.9 \dagger$ \\
\hline Folate $(\mathrm{nmol} / \mathrm{L})$ & $130.8 \pm 3.8$ & $141.7 \pm 11.2$ & $172.7 \pm 27.2$ & $35.5 \pm 11.8^{* \dagger}$ & $86.9 \pm 15.5$ & $69.0 \pm 13.8 \ddagger$ & $33.6 \pm 10.7 \dagger$ & $27.6 \pm 14.9 \dagger$ \\
\hline $\mathrm{HCY}(\mu \mathrm{mol} / \mathrm{L})$ & $5.6 \pm 2.2$ & $6.2 \pm 0.7$ & $6.1 \pm 0.5$ & $20.4 \pm 2.3^{* \dagger}$ & $6.8 \pm 0.3$ & $6.5 \pm 0.3$ & $13.3 \pm 1.2 \dagger$ & $21.2 \pm 1.6 \dagger+$ \\
\hline
\end{tabular}

Data are mean \pm SD and were obtained from 8 individuals for adult females and 12 individuals issued from four different litters for 21-d-old progeny. Adult females were tested before receiving their experimental (normal or deficient) diet (d 0) and then $30 \mathrm{~d}$ later. The progeny was tested at $21 \mathrm{~d}$ of age. C, $\mathrm{H}, \mathrm{D}$, and HD refer to the various experimental groups as defined in "Methods." Statistically significant differences: Mann-Whitney: * $p<0.02$ (d $30 v s \mathrm{~d} 0$ ); $\dagger p<0.01$ (deficient diet $v s$ normal diet); ANOVA: $\ddagger p<0.05$ (hypoxia $v s$ no hypoxia). n.d., not determined.
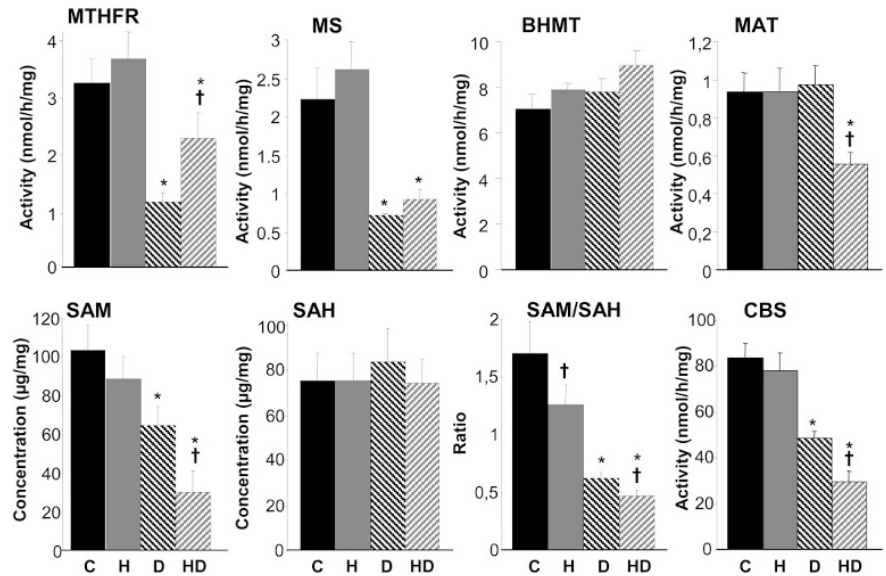

Figure 3. Effects of deficient diet and hypoxia on the various pathways involved in the monocarbon metabolism in 21-d-old rats. Data are mean $\pm \mathrm{SD}$. For each group, 12 rats from four different litters were studied. Statistically significant differences (ANOVA): $* p<0.01$ (deficient regimen $v s$ normal regimen), $\dagger p<0.05$ (hypoxia $v s$ no hypoxia).

various experimental groups, and remained around $80 \mu \mathrm{g} / \mathrm{mg}$ protein. From these data, an index of global cell methylation can be estimated in the different groups by the calculation of the SAM/SAH ratio $(10,27)$. This ratio decreased from $1.62 \pm$ 0.30 in $\mathrm{C}$ group to $0.61 \pm 0.06$ in $\mathrm{D}$ group $(p<0.01)$. Consistently, a significant decline was also recorded between $\mathrm{H}$ and $\mathrm{HD}$ groups $(1.26 \pm 0.20$ versus $0.46 \pm 0.06, p<0.05)$. An important feature was that a significant difference was detected between $\mathrm{C}$ and $\mathrm{H}$ groups as well as between $\mathrm{D}$ and $\mathrm{HD}$ groups, indicating that hypoxia seemed to exacerbate the effects of nutritional deficiency (Fig. 3).

In addition, a fall of MTHFR activity was recorded in rats exposed to the deficient diet $(0.9 \pm 0.2 \mathrm{nmol} / \mathrm{h} / \mathrm{mg}$ in group D versus $3.5 \pm 0.5 \mathrm{nmol} / \mathrm{h} / \mathrm{mg}$ in group $\mathrm{C}, p<0.01)$. Hypoxia had no influence on individuals normally fed, whereas it appeared to significantly attenuate the decrease in MTHFR activity recorded in response to the deficient diet (Fig. 3).

As a complement to these studies, mRNA levels of MS and CBS were analyzed. The rat group fed with a deficient diet (D) showed a significant decrease of the $M S / L 27$ mRNA ratio ( $p<$ 0.05 ) compared with the control group (Fig. $4 A$ ), whereas the hypoxic treatment did not influence this ratio. Regarding CBS mRNA transcripts, no significant differences were found between $C B S / L 27$ ratio values issued from the various experimental groups (Fig. 4B).
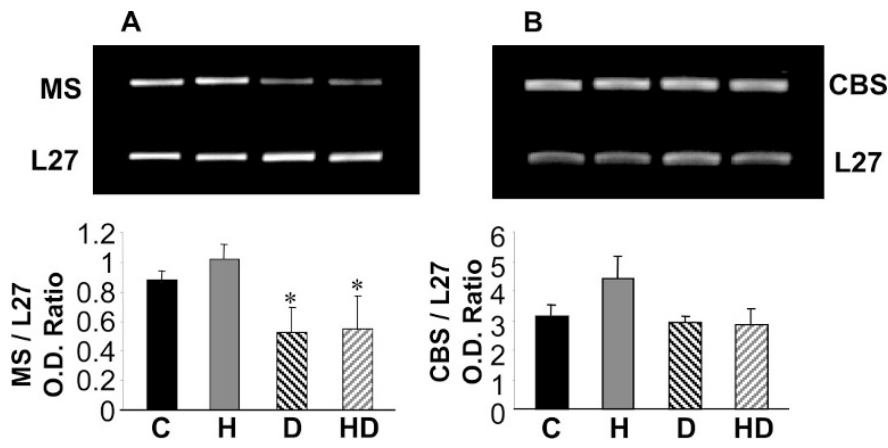

Figure 4. Effects of deficient diet and hypoxia on MS and CBS mRNA levels in the liver of 21-d-old rats. Data are mean \pm SE and are expressed as MS/L27 and CBS/L27 relative densitometric values. For each group, three rats were studied. Statistically significant differences (ANOVA): $* p<0.05$ (deficient regimen $v s$ normal regimen).

Correlation studies. According to multiple regression and univariate z-correlation analyses, vitamin B12 was found to be a determinant of MS activity $(p=0.0179)$, folate a determinant of MTHFR activity $(p=0.0023)$, and the SAM/SAH ratio a determinant of CBS activity $(p=0.0016)$.

Plasma concentration of HCY was significantly correlated to concentrations of SAM $(p<0.0002)$, folate $(p<0.0001)$, and vitamin B12 $(p<0.0001)$ as well as to MTHFR $(p=0.0061)$ and MS $(p=0.0320)$ activities.

Finally, both animal size and body weight were significantly correlated $(p<0.0001)$ to plasma concentrations of vitamin B12, folate, and HCY in 21-d-old rat pups.

\section{DISCUSSION}

When they were exposed to a vitamin-deficient diet in utero and then through their mothers' milk, rat pups exhibited a high score of perinatal mortality and sustained growth retardation. The present study also showed that such a diet produced a significant hHCY, in line with long-lasting metabolic disturbances. Mild neonatal hypoxia appeared to potentiate the long-term effects of the diet on HCY metabolism, indicating that it may potentially aggravate the adverse consequences of hHCY on the overall health status.

Methyl-deficient diets have previously been used in adult rats to induce hHCY at levels that are similar to those recorded in vitamin B-deficient humans (15-100 $\mu \mathrm{M}$ HCY) (10). Such diets impair HCY remethylation as they usually combine deficiency in vitamin B12 and folate, absence of choline, and low 
concentrations of methionine (36). In the present study, vitamin B2 was additionally omitted in the deficient diet since i) this compound is another key determinant of HCY remethylation, acting as a coenzyme for MTHFR and MS reductase (37), and ii) because the synthesis of coenzyme B2 is defective in malnourished children (28). Vitamin B6, the cofactor of CBS in HCY catabolism, was not removed from the deficient diet since it is not directly involved in the remethylation pathway.

Under these conditions, rat pups developed hHCY at a level comparable to that reported in other studies on adult rats (36). The effect of the deficient diet on the plasma vitamin B12 concentration was more dramatic in the offspring than in their mothers. It has been well documented that vitamin B12 deficiency may have long-lasting adverse effects in children (38). Consistent with our data, lower birth weight was recorded in rats in cases of marginal vitamin B12 intake during gestation (39). Growth retardation was shown to persist throughout the first year of life even when pups received adequate dietary vitamin B12. Additionally, offspring from deficient dams showed more liability to various types of infections.

In offspring subjected to the deficient diet, liver activities of CBS and MS were reduced. Decrease in CBS activity was not directly dependent on the vitamin deficiency, since the cofactor of this enzyme is vitamin B6, a compound that was not omitted from the diet. Instead, it could be related to the reduced concentrations of SAM in the deficient pups, considering the activating effect of this metabolite on CBS. On the other hand, the vitamin deficiency did not modify the transcription of the $C B S$ gene. MS activity is strongly dependent upon the availability of vitamin B12, and this certainly explains its substantial decrease after exposure to the deficient diet. Several studies support a role of vitamin B12 at the MS protein level. Yamada and colleagues (40) have suggested that low MS activity in vitamin B12-deficient rats can be explained by a reduced stabilization of the enzyme by its co-enzyme. In a previous study from our laboratory, it was observed that gastrectomized adult rats subjected to a methyl-deficient diet exhibited a reduced liver MS activity without any change of MS transcript level (36), and it has been recently reported that vitamin B12 may induce translational up-regulation of MS in cell culture by shifting the mRNA from the ribonucleoprotein to the polysome pool (41). In the present study, however, a modest but significant decrease in the amount of MS mRNA was detected under the conditions of deficient diet. Specific characteristics of our model, in particular the early and long-lasting exposure of rat fetuses to the vitamin B2-deprived deficient diet, may explain, at least in part, this apparent discrepancy with previous reports. In this respect, the absence of vitamin B2 in the diet used in the present study may also account for the reduction of MTHFR activity recorded in deficient rat pups, inasmuch as vitamin B2 is a co-factor for this enzyme.

The decline of SAM concentration might reflect a decreased remethylation of HCY rather than a decreased adenosylation of methionine, inasmuch as MS activity, but not that of MAT, was lowered in newborns subjected to the deficient diet.

We and others have shown that severe hypoxia in the newborn rat can induce tissue damage through apoptosis and alter normal development $(35,42)$. Conversely, mild hypoxia may exert beneficial effects by inducing tolerance to subsequent oxygen deprivation and by stimulating tissue repair and cell proliferation, as demonstrated both in vitro in cultured neurons (23) and in vivo in the newborn rat (26). We hypothesized that the same phenomenon may occur in the liver, and therefore submitted newborn rats to mild, nonlesioning hypoxia. The remethylation pathway of HCY may be a target for hypoxia (18-21). For instance, expression of the MAT gene has been shown to decrease in response to sustained hypoxia in isolated rat hepatocytes $(18,19)$. Such a down-regulation may be related to the stimulation of the inducible isoform of nitric oxide (NO) synthase and/or to a reduction of glutathione levels (20). The resulting decreases of mRNA abundance and of the corresponding enzyme activity, along with the reduction of SAM concentration in cells, could in turn trigger DNA hypomethylation, as previously documented, after methyl-deficient diet (43). Our results appear to be consistent with these findings. In addition, to our knowledge, they are the first to report a long-term influence of short hypoxia on HCY plasma concentration and CBS activity, an effect that was specifically evidenced in animals with vitamin-deficient diet.

Because CBS is the key enzyme of HCY catabolism, it may be speculated that its reduced activity accounts for the enhanced hHCY observed in deficient pups exposed to hypoxia. This may be due, at least partly, to the decreased concentration of SAM in hepatic cells. This product of MAT activity is a known activator of CBS. Under these conditions, it is therefore likely that a link exists between decreased MAT activity and subsequent decreases in SAM concentration and CBS activity in deficient pups exposed to neonatal hypoxia. This could also explain the relationship between HCY and SAM, which was depicted in these pups by univariate analysis.

A salient feature of our study is the long-term effects of hypoxia on activities of CBS, MTHFR, and MAT. Mechanisms accounting for such delayed changes remain to be elucidated and may possibly involve alteration of transcriptional activities, as previously shown for chronic hypoxia $(18,19,44)$. It has been recently shown that the effect of hypoxia on the expression of the MAT gene is under the influence of NO production (45). Whether or not the deficient diet modifies NO production should therefore be further investigated. It is known that cysteine-a product of the transsulfuration pathway of HCY metabolism-is the substrate for glutathione synthesis (46). The reduction of oxygen delivery has been shown to decrease glutathione production, leading to the inhibition of MAT transcription and activity $(18,19)$.

In conclusion, our results suggest that short episodes of hypoxia around birth may have a long-term aggravating effect on hHCY resulting from an inadequate vitamin status during pregnancy, mainly by decreasing HCY transsulfuration.

\section{REFERENCES}

1. Refsum H, Ueland PM, Nygard O, Vollset SE 1998 Homocysteine and cardiovascular disease. Annu Rev Med 49:31-62

2. Mattson MP, Shea TB 2003 Folate and homocysteine metabolism in neural plasticity and neurodegenerative disorders. Trends Neurosci 26:137-146

3. Clarke R, Smith AD, Jobst KA, Refsum H, Sutton L, Ueland PM 1998 Folate, vitamin B12, and serum total homocysteine levels in confirmed Alzheimer disease. Arch Neurol 55:1449-1455 
4. Brilakis ES, Berger PB, Ballman KV, Rozen R 2003 Methylenetetrahydrofolate reductase (MTHFR) $677 \mathrm{C} \rightarrow \mathrm{T}$ and methionine synthase reductase (MTRR) $66 \mathrm{~A} \rightarrow \mathrm{G}$ polymorphisms: association with serum homocysteine and angiographic coronary artery disease in the era of flour products fortified with folic acid. Atherosclerosis 168:315-322

5. Watanabe M, Osada J, Aratani Y, Kluckman K, Reddick R, Malinow MR, Maeda N 1995 Mice deficient in cystathionine beta-synthase: animal models for mild and severe homocyst(e)inemia. Proc Natl Acad Sci U S A 92:1585-1589

6. Chery C, Barbe F, Lequere C, Abdelmouttaleb I, Gerard P, Barbarino P, Boutroy JL Gueant JL 2002 Hyperhomocysteinemia is related to a decreased blood level of vitamin B12 in the second and third trimester of normal pregnancy. Clin Chem Lab Med 40:1105-1108

7. Pagan K, Hou J, Goldenberg RL, Cliver SP, Tamura T 2002 Mid-pregnancy serum homocysteine and B-vitamin concentrations and fetal growth. Nutr Res 22:1133-1141

8. Murphy MM, Scott JM, Arija V, Molloy AM, Fernandez-Ballart JD 2004 Maternal homocysteine before conception and throughout pregnancy predicts fetal homocysteine and birth weight. Clin Chem 50:1406-1412

9. Hague WM 2003 Homocysteine and pregnancy. Best Pract Res Clin Obstet Gynaecol 17:459-469

10. Burke G, Robinson K, Refsum H, Stuart B, Drumm J, Graham I 1992 Intrauterine growth retardation, perinatal death, and maternal homocysteine levels. N Engl J Med 326:69-70

11. Vollset SE, Refsum H, Irgens LM, Emblem BM, Tverdal A, Gjessing HK, Monsen AL, Ueland PM 2000 Plasma total homocysteine, pregnancy complications, and adverse pregnancy outcomes: the Hordaland homocysteine study. Am J Clin Nutr 71:962-968

12. de Vries JI, Dekker GA, Huijgens PC, Jakobs C, Blomberg BM, van Geijn HP 1997 Hyperhomocysteinaemia and protein $\mathrm{S}$ deficiency in complicated pregnancies. Br J Obstet Gynaecol 104:1248-1254

13. Mills JL, McPartlin JM, Kirke PN, Lee YJ, Conley MR, Weir DG, Scott JM 1995 Homocysteine metabolism in pregnancies complicated by neural tube defects. Lancet 345:149-151

14. Knott L, Hartridge T, Brown NL, Mansell JP, Sandy JR 2003 Homocysteine oxidation and apoptosis: a potential cause of cleft palate. In Vitro Cell Dev Biol Anim 39:98-105

15. Rosenquist TH, Ratashak SA, Selhub J 1996 Homocysteine induces congenital defects of the heart and neural tube: effect of folic acid. Proc Natl Acad Sci USA 93:15227-15232

16. Boison D, Scheurer L, Zumsteg V, Rulicke T, Litynski P, Fowler B, Brandner S, Mohler H 2002 Neonatal hepatic steatosis by disruption of the adenosine kinase gene. Proc Natl Acad Sci U S A 99:6985-6990

17. Finkelstein JD 1998 The metabolism of homocysteine: pathways and regulation. Eur J Pediatr 157(suppl 2):S40-S44

18. Avila MA, Carretero MV, Rodriguez EN, Mato JM 1998 Regulation by hypoxia of methionine adenosyltransferase activity and gene expression in rat hepatocytes. Gastroenterology 114:364-371

19. Chawla RK, Watson WH, Jones DP 1996 Effect of hypoxia on hepatic DNA methylation and tRNA methyltransferase in rat: similarities to effects of methyldeficient diets. J Cell Biochem 61:72-80

20. Ito K, Miwa N, Hagiwara K, Yano T, Shimizu-Saito K, Goseki N, Iwai T, Horikawa S 1999 Regulation of methionine adenosyltransferase activity by the glutathione level in rat liver during ischemia-reperfusion. Surg Today 29:1053-1058

21. Chawla RK, Jones DP 1994 Abnormal metabolism of S-adenosyl-L-methionine in hypoxic rat liver. Similarities to its abnormal metabolism in alcoholic cirrhosis. Biochim Biophys Acta 1199:45-51

22. Capo-Chichi CD, Feillet F, Gueant JL, Amouzou K, Zonon N, Sanni A, Lefebvre E, Assimadi K, Vidailhet M 2000 Concentrations of riboflavin and related organic acids in children with protein-energy malnutrition. Am J Clin Nutr 71:978-986

23. Bossenmeyer-Pourié C, Lièvre V, Grojean S, Koziel V, Pillot T, Daval JL 2002 Sequential expression patterns of apoptosis- and cell cycle-related proteins in neuronal response to severe or mild transient hypoxia. Neuroscience 114:869-882

24. Carter AM 1989 Factors affecting gas transfer across the placenta and the oxygen supply to the fetus. J Dev Physiol 12:305-322
25. Chase PH, Volpe JJ, Laster L 1968 Transsulfuration in mammals: fetal and early development of methionine-activating enzyme and its relation to hormonal influences. J Clin Invest 47:2099-2108

26. Pourié G, Blaise S, Lièvre V, Vert P, Daval JL 2004 Non-lesioning neonatal hypoxia can induce long-term neurogenesis in the rat brain. Pediatr Res 55:25A

27. Bradford MM 1976 A rapid and sensitive method for the quantitation of microgram quantities of protein utilizing the principle of protein-dye binding. Anal Biochem $72: 248-254$

28. Amouzou EK, Chabi NW, Adjalla CE, Rodriguez-Guéant RM, Feillet F, Villaume C, Sanni A, Guéant JL 2004 High prevalence of hyperhomocysteinemia related to folate deficiency and the $677 \mathrm{C} \rightarrow \mathrm{T}$ mutation of the gene encoding methylenetetrahydrofolate reductase in coastal West Africa. Am J Clin Nutr 79:619-624

29. Taoka S, Ohja S, Shan X, Kruger WD, Banerjee R 1998 Evidence for heme-mediated redox regulation of human cystathionine beta-synthase activity. J Biol Chem 273:25179-25184

30. Chen Z, Chakraborty S, Banerjee R 1995 Demonstration that mammalian methionine synthases are predominantly cobalamin-loaded. J Biol Chem 270:19246-19249

31. Garrow TA 1996 Purification, kinetic properties, and cDNA cloning of mammalian betaine-homocysteine methyltransferase. J Biol Chem 271:22831-22838

32. Chamberlin ME, Ubagai T, Mudd SH, Wilson WG, Leonard JV, Chou JY 1996 Demyelination of the brain is associated with methionine adenosyltransferase I/III deficiency. J Clin Invest 98:1021-1027

33. Kutzbach C, Stokstad EL 1971 Mammalian methylenetetrahydrofolate reductase Partial purification, properties, and inhibition by S-adenosylmethionine. Biochim Biophys Acta 250:459-477

34. Delabar U, Kloor D, Luippold G, Muhlbauer B 1999 Simultaneous determination of adenosine, S-adenosylhomocysteine and S-adenosylmethionine in biological samples using solid-phase extraction and high-performance liquid chromatography. J Chromatogr B Biomed Sci Appl 724:231-238

35. Grojean S, Schroeder H, Pourié G, Charriaut-Marlangue C, Koziel V, Desor D, Vert P, Daval JL 2003 Histopathological alterations and functional brain deficits after transient hypoxia in the newborn rat pup: a long term follow-up. Neurobiol Dis 14:265-278

36. Brunaud L, Alberto JM, Ayav A, Gerard P, Namour F, Antunes L, Braun M, Bronowicki JP, Bresler L, Gueant JL 2003 Vitamin B12 is a strong determinant of low methionine synthase activity and DNA hypomethylation in gastrectomized rats. Digestion 68:133-140

37. Poirier LA 2002 The effects of diet, genetics and chemicals on toxicity and aberrant DNA methylation: an introduction. J Nutr 132:2336S-2339S

38. Black MM 2003 Micronutrient deficiencies and cognitive functioning. J Nutr 133:3927S-3931S

39. Newberne PM, Young VR 1973 Marginal vitamin B 12 intake during gestation in the rat has long term effects on the offspring. Nature 242:263-265

40. Yamada K, Kawata T, Wada M, Isshiki T, Onoda J, Kawanishi T, Kunou A, Tadokoro T, Tobimatsu T, Maekawa A, Toraya T 2000 Extremely low activity of methionine synthase in vitamin B-12-deficient rats may be related to effects on coenzyme stabilization rather than to changes in coenzyme induction. J Nutr 2000 130:1894-1900

41. Oltean S, Banerjee R 2003 Nutritional modulation of gene expression and homocysteine utilization by vitamin B12. J Biol Chem 278:20778-20784

42. Daval JL, Pourié G, Grojean S, Lièvre V, Strazielle C, Blaise S, Vert P 2004 Neonatal hypoxia triggers transient apoptosis followed by neurogenesis in the rat CA1 hippocampus. Pediatr Res 55:561-567

43. Garcia-Trevijano ER, Martinez-Chantar ML, Latasa MU, Mato JM, Avila MA 2002 NO sensitizes rat hepatocytes to proliferation by modifying S-adenosylmethionine levels. Gastroenterology 122:1355-1363

44. Sonna LA, Cullivan ML, Sheldon HK, Pratt RE, Lilly CM 2003 Effect of hypoxia on gene expression by human hepatocytes (HepG2). Physiol Genomics 12:195-207

45. Ruiz F, Corrales FJ, Miqueo C, Mato JM 1998 Nitric oxide inactivates rat hepatic methionine adenosyltransferase in vivo by S-nitrosylation. Hepatology 28:1051-1057

46. Hargreaves IP, Lee PJ, Briddon A 2002 Homocysteine and cysteine-albumin binding in homocystinuria: assessment of cysteine status and implications for glutathione synthesis? Amino Acids 22:109-118 